\section{LA EXPOSICIÓN SOBRE SABOGAL EN EL MALI}

La exposición que el MALI (Museo de Arte de Lima) ha dedicado a Sabogal pone nuevamente sobre el tapete el caso del pintor cajabambino, renueva la discusión sobre sus valores plásticos y sobre su legado a la cultura de nuestro pais.

Sabogal ha sido un pintor que ha generado corrientes contradictorias de crítica a lo largo de su vida: alabado y mimado primero por una burguesía desconcertada, luego vituperado y renegado por los artistas más jóvenes, lo cierto es que supo "capear el temporal" con una buena dosis de paciencia esperando su "hora" y una fe inquebrantable en su trabajo. Cómo debió entusiasmar el primigenio Sabogal al severo Teófilo Castillo para que dijera, luego de visitar su taller, "Acabo de ver las telas pintadas por un joven peruano (...) Es un arte nuevo refrescado por la brisa de América, de un valor plástico sólido y sincero. Ya verán ustedes. Prepara una exposición que será un bofetón para los imitadores de la pintura europea (...) absolutamente nacional, racial en paisajes y figuras".' Pero años más tarde, cuando Sabogal asume la dirección de la ENBA, ya se deja sentir las críticas de los jóvenes alumnos que, en boca de Luis Fernández Prada, acusan a la Dirección de haber causado la frustración de "muchachos entusiastas e ilusos".

¿Cómo veian la pintura de Sabogal sus contemporáneos? Luis E. Varcárcel había notado en la primera pintura de Sabogal "el aspecto colonial e hispánico del Cuzco" y José Gálvez, el poeta de la Lima del pasado, manifestó en un artículo: Sabogal, como buen serrano, es profundamente nacional y profundamente español. ${ }^{2}$ En ese momento, que coincide con los festejos del Centenario, los dos intelectuales percibieron el legado sutil de la Madre Patria. Teófilo Castillo hace más extensiva su caracterización al decir que Sabogal llega a definir bien hondo, más quizá que Lasso (sic) que ya es mucho decir, el alma peruana. Es clara e incuestionable la opción mestiza y criolla del pintor de Cajabamba desde el inicio de su carrera que alternó paralelamente con el tema indígena. Después de todo fueron sus opositores los que inventaron el mote de "indigenistas", dejando en el ambiente la idea de un Sabogal pintor de indios que es como siempre se lo ha ubicado en la historia del Perú.

Hoy, con la ventaja de la distancia que hace posible una mirada retrospectiva, y con el trabajo infatigable de los estudiosos del arte peruano, se ha logrado llevar al Museo de Arte de Lima una buena cantidad de obras y presentarlas al público, último juez al fin y al cabo, de la obra de los artistas. Toda exposición museográfica es como una "performance", donde siempre existe, por un lado, el temor del artista de su presentación ante el público, y por otro, la expectativa de éste por ver lo que se ha publicitado. En el caso que nos ocupa el temor del artista ya no cuenta, como es obvio, pero si su "fama" que se presenta como si estuviera vivo.

Hay dos criterios museográficos que pueden usarse para las retrospectivas: hacer una selección de lo más representativo de un artista que haga posible, sin embargo, el estudio de su desarrollo estilístico a través de sus etapas, sus aportes y sus vacilaciones, o presentar toda la obra que pueda conseguirse, sin ninguna selección cualitativa o estética. Los

2 Majluf, Wuffarden, Sabogal, MALIBCP, Lima, 2013, pp. 27-36. 
curadores de la exposición, Majluf y Wuffarden, han preferido la segunda opción aludiendo que el público tiene derecho a ver toda la obra de Sabogal y hacerse una idea del valor de su propuesta.

Los dos son criterios válidos; sin embargo se podría objetar que el segundo, pone al desnudo la producción pictórica de Sabogal mostrando los logros más altos junto con las búsquedas y los escarceos y esto, desconcierta al público.

En la trabajosa vida de un artista no todo lo que produce es una obra candidata al museo; muchas veces la voluntad de "hacer obra" no coincide con una forma lograda de la que pueda decirse que se eslabona a las anteriores o constituye una nueva manera digna de tenerse en cuenta para juzgarlo. Con Sabogal sucede que la voluntad de hacer es más fuerte que el resultado artístico, de ahí que produjo algunas obras que son apuntes, pruebas, ejercicios en busca de una definición. En medio de esa diversidad sin embargo, sí se puede seguir las trazas de ciertas maneras que en secuencia podrían dar razón de alguna coherencia formal, para lo cual tendría que hacerse una saludable selección, si seguimos el primer criterio.

Líneas arriba hemos hablado de la exposición como "performance" y creo que podemos apelar ahora a un ejemplo nada banal: cuando a alguien se le ocurre producir un disco de un cantante clásico conocido se busca aquellas canciones donde la estrella luce sus mejores cualidades y el buen estado físico de su voz. A ningún productor con se le ocurriría incluir en la selección alguna canción desafinada o mal ejecutada.

Hay otro argumento válido: la museografia consiste no solamente en saber colgar cuadros sino en el arte de "dar sentido" a las obras; esto precisamente la distingue de la mera decoración. La labor curatorial es museográfica no solo porque hace posible visualizar la muestra sino porque, insisto, le da sentido.

Sin embargo la exposición tiene muchos méritos que no se le puede regatear y el primero y más plausible es el hecho de haber planteado el "estado de la cuestión" sobre Sabogal en nuestro medio, donde algunas exposiciones parciales no han hecho más que repetir lo escrito hace tiempo. Otro aporte de relieve es sin duda el esclarecimiento sobre la condición criolla de la obra de Sabogal, y no solo indígena, como lo declararon sus detractores en la década del 30. Es tan importante este punto que los curadores determinaron crear una sala especial para explicar la conversión paulatina de la temática criolla como resultado de la mezcla de "todas las sangres". Por último, y no por eso menos importante, la edición del trabajo de investigación de Natalia Majluf y Luis Eduardo Wuffarden, ha resultado, como lo esperábamos, la summa sabogalense sobre el pintor cajabambino, ejemplo de conocimiento sobre el tema, profesionalismo y modelo para la generación de relevo que les seguirá. 